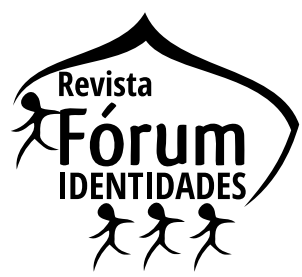

\title{
RESISTÊNCIA E LUTA EM A MORTE DO VELHO KIPACAÇA'
}

\author{
RESISTANCE AND DEATH IN \\ A MORTE DO VELHO KIPACAÇA
}

\author{
Marcos Antonio de Oliveira² \\ Verônica Maria de Araújo Pontes ${ }^{3}$
}

\begin{abstract}
Resumo: Este artigo tem como objetivo geral analisar a importância das tradições culturais na literatura angolana em $A$ morte do velho Kipacaça, de Boaventura Cardoso (2004). Como objetivos específicos, busca-se associar o contexto da obra citada com as lendas brasileiras, como o Caipora e o Curupira, e relacionar o processo literário angolano com o Modernismo brasileiro. Durante séculos, os angolanos passaram por um processo de assimilação, o que os levou a questionar e a fortalecer sua própria cultura, a exemplo do que aconteceu também com o Modernismo brasileiro, que buscava criar uma identidade nacional. Diante do processo de formação de seu povo, os escritores vivenciaram duas realidades: a da vida do europeu e a do africano, notadamente em Angola, onde a literatura ainda trazia os traços da oralidade como parte da cultura local. Para isso, utiliza-se a pesquisa bibliográfica. Amparado em autores como Bakthin (Volochínov) (1992); Ferreira (2010); Fonseca; Moreira (2007), Cardoso (2004), entre outros, pode-se compreender a contribuição das tradições para a formação da identidade cultural do angolano.
\end{abstract}

Palavras-chave: Construção de identidade. Cultura. Resistência.

\begin{abstract}
This article aims to analyze the importance of cultural traditions in Angolan literature in A Morte do Velho Kipacaça by Boaventura Cardoso (2004). As specific objectives, it seeks to associate the context of the quoted work with brazilian legends, such as Caipora and Curupira and it also seeks to relate the angolan literary process with Brazilian Modernism. Over the centuries, angolans went through a process of assimilation, which took them to question and strengthen their own culture, an example of what also happened to Brazilian Modernism, which sought to create a national identity. Faced to the process of fomartion of their own people, writers experienced two realities: the life of europeans and africans, notably in Angola, where literature stil brought traces of orality as parte of the local culture. For this a bibliographic research is used. Supported by authors such as Bakthin (Volochinov) (1992); Ferreira (2010); Fonseca; Moreira (2007); Cardoso (2004), among other, it is possibe to understand the contribution of tradition for the formation of the angolan cultural identity.
\end{abstract}

Keywords: Identity construction. Culture. Resistance.

\footnotetext{
${ }^{1}$ Artigo recebido em 14 de agosto de 2021 e aceito para publicação em 26 de setembro de 2021.

${ }^{2}$ Mestre - Universidade do Estado do Rio Grande do Norte (UERN); membro do Grupo de Pesquisa Literatura, Tecnologias e Novas Linguagens. E-mail: professor_marcosantonio@hotmail.com. ORCID: https://orcid. org/0000-0002-2987-3628.

${ }^{3}$ Doutora - Universidade do Estado do Rio Grande do Norte (UERN)/Instituto Federal de Ciência e Tecnologia do Rio Grande do Norte (IFRN); membro do Grupo de Pesquisa Literatura, Tecnologias e Novas Linguagens. E-mail: pontes. veronica@ifrn.edu.br. ORCID: https://orcid.org/0000-0003-2774-4491.
} 


\section{Introdução}

Brasil e África têm uma identificação muito próxima com relação à sua História. Política e culturalmente, os dois países são ligados pelo fato de que muitos dos hábitos, costumes e História compartilhados são ainda herança dos antepassados que viveram nos países africanos. Na literatura, há também uma ligação muito forte, visto que, do período literário denominado Modernismo, alguns escritores brasileiros se tornaram referência para os poetas e autores africanos, como os modernistas Manuel Bandeira (1886-1968), Mário de Andrade (1893-1945) e João Guimarães Rosa (1908-1967).

Este artigo tem como objetivo geral analisar a importância das tradições culturais na literatura angolana em $A$ morte do velho Kipacaça, de Boaventura Cardoso (2004). Como objetivos específicos, associar o contexto da obra citada com as lendas brasileiras, como o Caipora e o Curupira, e relacionar o processo literário angolano com o Modernismo brasileiro. Para isso, este trabalho parte de uma pesquisa bibliográfica, baseada em autores como Bakthin (Volochínov) (1992); Ferreira (2010); Fonseca; Moreira (2007), Cardoso (2004), entre outros. Com isso, pode-se compreender a contribuição das tradições para a formação da identidade cultural do angolano.

Bem ao estilo do Modernismo brasileiro, a literatura africana também buscava se consolidar como uma arte calcada na reflexão sobre o próprio povo, assim como foi a escrita modernista, cujo embate se baseava na busca de uma identidade nacional que transcendesse uma literatura europeizada. Com isso, elementos da cultura brasileira passaram a fazer parte dos romances e poemas, bem como cenas prosaicas, que aproximavam o leitor dos textos literários, fazendo-os se identificarem com a histórias.

Manuel Bandeira, por exemplo, em seu célebre poema "Os sapos", que abriu a Semana de Arte Moderna, em 1922, inseriu nos versos finais um trecho de uma cantiga de roda muito utilizada pelas crianças: "[...] que soluças tu/transido de frio/sapo cururu/Da beira do rio...” (BANDEIRA, 1993, p. 81).

Dessa forma, com essa busca de uma identidade que apresentasse um país mais real, fugindo do estereótipo de idealização do Romantismo, por exemplo, tanto a literatura brasileira quanto a angolana abordaram também

não apenas aspectos que revelam a competência estética de seus autores em criar uma literatura autônoma e original, mas também que demonstrem como essa literatura pode interagir com todo o processo de construção da identidade cultural africana, equacionando, assim, as contradições que foram historicamente implantadas por um sistema de colonização (SILVA, 2011, p. 1-2). 
Esse processo de construção de identidade, segundo o autor citado, também se baseava na luta contra a colonização. Aqui podemos nos referir a uma colonização cultural, pois muitos dos autores frequentavam outras instituições em países europeus e, assim, acabavam trazendo os costumes aprendidos lá, além da colonização imposta pelos europeus.

Em Angola, Cabo Verde, Guiné-Bissau, Moçambique e São Tomé e Príncipe, o escritor africano vivia, até a data da independência, no meio de duas realidades às quais não podia ficar alheio: a sociedade colonial e a sociedade africana. A escrita literária expressava a tensão existente entre esses dois mundos e revelava que o escritor, porque iria sempre utilizar uma linguagem europeia, era um "homem-de-dois-mundos" (FONSECA, 2007, p. 14).

Porto (2016) compara o desenvolvimento da literatura em Angola com o de outros países para mostrar o foco dos escritores, os quais traziam uma literatura de combate, a qual tentava lutar contra a exploração econômica e cultural.

Diferentemente do que ocorrera em outros países colonizados pelos portugueses, tal como no Brasil, onde a literatura nasceu moldada pelos padrões de escrita europeus tanto nos aspectos formais quanto temáticos, havendo continuidade desses diálogos durante séculos, em Angola a literatura surge e se desenvolve com o olhar local, voltada para a realidade de seu país (PORTO, 2016, p. 11).

Esse olhar local de que fala a autora é voltado para a luta contra o processo colonizatório, com os angolanos resistindo e se afirmando como africanos, como negros e conscientes de que precisavam enfrentar o "invasor". Entende-se como invasor tudo aquilo que vem de fora com a intenção de modificar os costumes locais e impor uma nova cultura, a qual passa longe do que se vivencia localmente.

Manuel Bandeira (1886-1968) e Mário de Andrade (1893-1945) fizeram parte da geração modernista responsável por combater um pensamento colonial, cuja compreensão ainda estava ligada a uma arte europeizada, como se somente o que viesse de fora tivesse valor. Conforme Bosi (2015, p. 364), ao se referir ao contexto do Modernismo, ressalta: "Dividido em a ânsia de acertar o passo com a modernidade da Segunda Revolução Industrial, de que o futurismo foi testemunho vibrante, e a certeza de que as raízes brasileiras, em particular indígenas e negras, solicitavam um tratamento estético, necessariamente primitivista".

Ambos os modernistas defenderam uma antropofagia na arte brasileira, buscando aproveitar melhor as culturas tanto estrangeiras quanto nacionais e transformar o Brasil em um país rico culturalmente, aproveitando a cultura vinda da África e já estabelecida em solo brasileiro, unindo-a aos costumes locais. 
Entre os países africanos que trouxeram em sua essência esse combate à colonização e que contribuiu amplamente para a consolidação da construção da identidade cultural brasileira está Angola, localizado na costa ocidental da África e banhado pelo Oceano Atlântico.

Os primeiros registros literários, de acordo com Soares (2001), surgem por volta de 1600, por influência dos jesuítas que aportaram no país. Ainda segundo o autor, há um equívoco quando se demarca o início da literatura angolana por volta de 1950 do século XX. Isso porque já havia a realização de concursos poéticos apoiados pelo Governador-Geral no século XVII.

Segundo Silva (2011), a literatura angolana pode ser dividida em três momentos: a primeira fase, marcada pela expressão tipicamente colonial e nativista, a fase da alienação, com obras escritas por volta de 1800, surgindo a partir disso o anticolonialismo; a segunda, uma fase pré-independentista, com escritos da primeira metade do século XX; e a terceira, com a fase independente, de 1950 em diante, exprimindo a afirmação da negritude.

Considera-se que o estudo da produção poética dos escritores africanos pode ser feito mediante uma abordagem diacrônica das literaturas a que pertencem, o qual observe: as dificuldades do sujeito poético de se encontrar com seu universo africano; o fato de que grande parte da produção literária reflete a busca da identidade cultural e a tomada progressiva de uma consciência nacional; o fato de que é sempre possível detectar, nos autores, o momento poético da luta, que se configura num discurso de resistência e de reivindicação por mudanças; as mudanças que encaminham para um processo de releitura constante que liga o presente e o passado na construção de uma África que se renova continuamente (FONSECA; MOREIRA, 2007, p. 15).

É com esse estudo que se pode compreender melhor a trajetória da escrita dos autores africanos, os quais apresentam a África como um lugar de resistência e de luta, um continente que se renova constantemente, e não apenas um lugar de miséria e de abandono.

$\mathrm{Na}$ prosa, a literatura angolana atinge sua maturidade com autores como Boaventura Cardoso, o qual, para Saraiva (2016), busca desalienar a literatura, fazendo-a cumprir uma função que não apenas a de se mostrar como arte, mas também de servir de meio para denunciar a situação sócio-político-cultural de Angola.

Nascido em São Paulo de Assunção de Luanda, em julho de1944, filho de Dona Rita e Sô Cardoso, enfermeiro-dentista, foi morar em Malanje, em 1955, aos oito anos, quando seu pai foi transferido, completando o curso primário, na Escola 74 e o secundário na Escola Industrial e Comercial, bem como a Seção Preparatória aos 
Institutos. Passou pelo Seminário onde conheceu jovens engajados na luta libertária, o que possivelmente o motivou a cultivar essas ideias (FERREIRA, 2010, p. 169).

O fato de ter, em sua formação, cultivado ideias libertárias contribuiu para que Boaventura Cardoso lutasse pela independência tanto política quanto linguística, já que em suas obras o uso da linguagem busca abrir caminhos para uma nova Angola, cheia de sonhos, de inovações e de esperança, como veremos na seção seguinte, com a obra $A$ morte do Velho Kipacaça (2004), em que o autor joga com as palavras, trazendo à tona uma transgressão linguística.

É essa transgressão que marcará as obras de Boaventura Cardoso, enfocando a identidade do angolano, como afirma Laranjeira (2017, p. 21):

Porém, a despeito das teorias pós-modernas da deslocalização e do desenraizamento, da viagem e da desterritorialização, da deriva e da mobilidade, da mistura e do hibridismo, do não-lugar e do entre-lugar, os seres humanos, na sua grande maioria, continuam a identificar-se com territórios, paisagens, costumes, culturas, heranças, permanências, que lhes conferem um sentido de pertença, de ancoragem e de identidade com certo grau de estabilidade (embora com as suas modificações temporais e espaciais), sem os quais as sociedades seriam conjuntos de seres totalmente desgarrados, insulados na solidão coletiva, à deriva e sem balizas culturais de referência.

É essa busca da identidade e da identificação com suas raízes, com sua cultura, que vai culminar em uma literatura em que a oralidade está bem presente, tendo em vista sua história baseada nas narrações orais, como ressaltam Fonseca e Moreira (2007, p. 31).

Em 1948, estudantes e intelectuais angolanos - negros, brancos e mestiços - lançaram, em Luanda, o brado "Vamos descobrir Angola", que tinha como objetivos romper com o tradicionalismo cultural imposto pelo colonialismo; debruçar-se sobre Angola e sua cultura, suas gentes e seus problemas; atentar para as aspirações populares, fortalecendo as relações entre literatura e sociedade; conhecer profundamente o mundo angolano de que eles faziam parte mas que não figurara nos conteúdos escolares aos quais tiveram acesso.

No próximo tópico, poderemos perceber os traços de oralidade na literatura angolana e atentar para as aspirações populares na obra $A$ morte do Velho Kipacaça (2004). 


\section{A oralidade e as tradições culturais como símbolo de resistência}

Ambientado às margens do rio Pombuiji, o enredo de $A$ morte do velho Kipacaşa nos apresnta os ritos vivenciados pelos povos antigos africanos. Ritos esses que constroem a história de um povo e o guiam para uma convivência aparentemente harmoniosa entre os pares. Quando se fala "harmoniosa" é no sentido de vida em comunidade, onde todos se conhecem e vivem suas tradições. No conto de Boaventura Cardoso, é possível entrar em contato com tradições africanas repletas de simbologias, como, por exemplo, o fato de um caçador que morre durante a caçada e cujo corpo não é encontrado trazer azar para a comunidade. Isso desencadeia uma busca incessante.

Como é possível associar um fato a outro sem que haja uma comprovação? Como o fato de não ter chuva pode ser consequência do desaparecimento do caçador? É a cultura de um povo que apresenta essas vivências e as toma como verdade, sem que ousem desafiá-las. Logo no início, o Velho Bernardo levanta uma dúvida, o que demonstra conhecimento por ser ele alguém mais velho, que inspira respeito e demonstra sabedoria. É parte da cultura: os mais velhos são mais sábios, pois têm experiência. O Velho Bernardo, com letra maiúscula, indicando nome próprio, como um sinal de respeito, levanta uma dúvida: "[...] esta chuva que não vem tem de ter uma explicação" (CARDOSO, 2004, p. 36). Ao afirmar "tem de ter", pressupõe-se uma obrigatoriedade, ou seja, isso não pode ficar sem resposta. Ele sabe, entende os sinais.

Cunha (2009), ao tratar da importância dos mais velhos na cultura africana, ressalta a sabedoria contida nessas pessoas e a referência que elas se tornam para toda a comunidade. Elas são as guardiãs da memória, das histórias de todos que fazem parte daquele grupo:

Em algumas sociedades africanas era comum ouvir-se, quando morria um velho, que morria uma biblioteca, porque o conhecimento (de natureza história, jurídica, religiosa) sobrevivia na cabeça das pessoas e estas se constituíam referências às quais era possível recorrer sempre que necessário (CUNHA, 2009, p. 109).

Com isso, conforme a autora supracitada, os mais velhos são os contadores não só de histórias reais, mas também das histórias contadas ao longo das gerações. A morte do Velho Kipacaça gira em torno da morte do caçador Kipacaça, que sai para uma caçada e não volta, sendo considerado morto pela comunidade. Isso é o bastante para todos associarem essa morte ao fato de não ter chuva. É a resposta que o Velho Bernardo queria. Seguindo as tradições locais, ele sabia que o caçador desaparecido era responsável por isso. 
Dizem os mais velhos, no conto, que isso é um sinal de que o desaparecimento de Kipacaça trouxe azar para a comunidade. Por isso, é preciso desvendar esse mistério: encontrar o corpo do caçador. Mesmo assim, ainda havia uma esperança de que ele estivesse vivo: “[...] Kipacaça não lhe podiam matar ngó assim sem ninguém saber se ele mesmo Kipacaça morreu ou não, coitadito quem sabe às vezes estava na mata perdido" (CARDOSO, p. 44).

Para desvendar um mistério, é necessário recorrer ao Velho Kufuca, um sábio que já desvendara outro mistério no passado. Mais uma vez, a adjetivo Velho aparece com letra maiúscula. Nas culturas africanas, o velho está associado ao feiticeiro. É ele quem desvenda os mistérios presentes no mudo físico através de estratégias sobrenaturais, como o fato de beber bulungo para descobrir quem matou Kipacaça. A bebida fará o assassino se entregar através do espirro. E assim é feito. Até que o verdadeiro assassino, Kapiapia, é descoberto e morto pelos presentes.

As ações dos personagens são baseadas nos costumes locais. $\mathrm{O}$ fato de a mulher de Kipacaça, Tereza, descobrir por sonho que alguma coisa estava para acontecer; a bebida que descobriria o assassino; a resposta do mistério ser descoberta por um feiticeiro; a dança ao final do conto; o fato de Kipacaça aparecer em meio à noite, saindo da floresta, acompanhado por animais; além das expressões orais utilizadas pelas personagens, evidenciam a importância do cotidiano para se contar a história do caçador que saiu para uma caçada e não mais voltou.

Ainda hoje, mesmo na cultura urbanizada, é possível encontrar pessoas mais velhas que seguem costumes locais de quando eram crianças. Esses costumes vêm de histórias que se ouviam a respeito de algumas tradições: sonhar com alguma coisa, por exemplo, pode ter uma interpretação de que algo bom ou ruim vai acontecer.

No conto angolano em evidência, outra estratégia para aproximar-se do cotidiano é a utilização do discurso indireto livre, o qual mescla a fala do narrador com a do personagem, como se fossem uma só, como no exemplo:

Tem silêncio. Quem sabe mesmo o velho Kipacaça está mesmo esta hora mesmo está lá nas alturas? Quem sabe ngó? Eh! Derepente, soluço imperceptível esventra barriga do ventre e estala. Agora soluço tem choro se generalizando (CARDOSO, 2004, p. 37 - grifo nosso).

Ao ouvir o relato de Kapiapia sobre o sonho, o narrador diz o que o Velho Bernardo Nilkila estava pensando, configurando-se um discurso que, mesmo sendo do narrador, pode ser atribuído ao pensamento do personagem. Essa mesma estratégia é utilizada por escritores modernistas para inserir o cotidiano nas histórias. Para Bakthin/Volochínov (1992, p. 185), 
[...] o autor apresenta a enunciação do herói como se ele se encarregasse dela, como se se tratasse de fatos e não simplesmente de pensamentos ou de palavras. [...] Ele participa por dentro dos atos e das palavras de seus heróis, coloca-se como seu intercessor e defensor.

De fato, ao unir os dois discursos, o narrador busca aproximar ainda mais o leitor, tentando fazê-lo se identificar com o dito, como se o próprio leitor fizesse os questionamentos e ele mesmo pensasse em uma resposta. É essa troca de pontos de vista entre narrador-personagem-leitor que dinamiza o conto a fim de trazer uma imersão mais acentuada na própria cultura local, já que o cotidiano é vivenciado com todas as suas tradições. Parreiras (2009, p. 113) diz que:

\begin{abstract}
Sobre a linguagem e a forma de apresentação das histórias, a estrutura de uma história da oralidade africana é, certamente, diferente da oralidade que marca um conto de fadas recolhido pelos irmãos Grimm, na Alemanha, ou recolhido por Câmara Cascudo, no Brasil. Nem sempre essa linguagem é respeitada e preservada, E o final feliz, presente em alguns contos de fadas, por exemplo, dos Grimm, nem sempre é característica das histórias de origem africana.
\end{abstract}

Dentro dessa perspectiva, de que as histórias orais africanas são diferentes das de outras culturas, de trazer para o conto o vivido no dia a dia, podemos perceber a importância da oralidade para a fluidez da história. É essa oralidade que vai enfocar que o enredo gira em torno de um lugar que preserva ainda sua cultura, visto que alguns elementos continuam no imaginário das pessoas, como as revelações pelo sonho, pelo feiticeiro, as crendices, como no trecho a seguir:

[...] - Sonhei. Eh! Sonhei ngó um sonho, tu foste na caça e não voltaste! - Mana Teresa se aliviou do nó que lhe estava na garganta. Kipacaça lê nos olhos da mulher, tem presságio qualquer, mas evitando dar mostras de receio e reage assim [...] (CARDOSO, 2004, p. 45).

Ao reafirmar o presságio no sonho, podemos identificar como as tradições angolanas são incorporadas para dar mais veracidade à história, simbolizando essa característica dos antepassados de se guiar pelo folclore.

Além disso, o conto apresenta também muitas expressões locais que, sem um conhecimento das tradições angolanas não é fácil de compreender. Por isso, o autor apresenta, ao final, um vocabulário com expressões utilizadas na obra típicas do contexto angolano. Expressões como "aamam'éé! (oh minha mãe); "ngó" (só - palavra denotativa); "pupangombe" (deusa da caça e protetora dos caçadores); "zé" (palavra denotativa de realce ou de ênfase), aparecem frequentemente dando ainda mais veracidade ao conto, identificando o leitor com as histórias orais contadas pelos mais velhos. 
Como já dito, na literatura angolana há uma aproximação com o Modernismo brasileiro, especificamente nas obras de Boaventura Cardoso ao inserir esses recursos em $A$ morte do velho Kipacaça, o que faz se aproximar do escritor brasileiro da terceira geração modernista João Guimarães Rosa (1908-1967), que também utilizou a cultura local e as tradições do sertão mineiro em várias de suas obras, como em Grande Sertão: Veredas (2006), por exemplo: “[...] Aperrei o nagã , precisei de dar um tiro - no mato - um tiraço que ribombou [...]” (GUIMARÃES ROSA, 2006, p. 292); “[...] Ei, pois, ele estava caipora. Logo vi [...]”. É como se o leitor fizesse parte daquele cenário e pudesse compreender tudo porque também vive aquilo. $\mathrm{O}$ mesmo acontece em $A$ morte do velho Kipacaşa.

Além disso, há, segundo Paganini (2007, p. 97), em ambas as obras, uma teatralização do discurso, "que seria um dos recursos utilizados por Guimarães Rosa para a inclusão de elementos da cultura acústica em sua literatura, ainda que essa encenação não se restrinja a esse único objetivo".

Depois de andarem pela floresta em busca do caçador e não encontrarem o seu corpo, as pessoas voltam para casa e fazem uma roda dançante para homenagear a memória de Kipacaça, com muito batuque e música. Até que surge algo inesperado.

O espírito do Velho Kipacaça surge imponente em cima de uma pacaça, carregando o fogo que ilumina tudo e depois entra na roda dançante. O fogo é um elemento importante na cultura dos povos angolanos: “[...] símbolo da transformação, o fogo, assim como a água, regenera e transforma, fazendo a mediação entre formas em vias de desaparecimento e em processo de criação" (PAGANINI, 2007, p. 102).

\section{Kipacaça e a caipora: símbolos de resistência}

$O$ velho caçador se torna o protetor da floresta e dos animais, bem ao estilo do personagem folclórico brasileiro Caipora. No Brasil, segundo a lenda, quando os caçadores adentram a floresta em busca de caça ou de destruir a mata, o ser mitológico aparece montado em um porco-do-mato, afugentando os caçadores ao fazer um barulho estridente, protegendo assim os animais de serem mortos. O Caipora é um ser que resiste à investida do invasor. A semelhança com Kipacaça está no fato de este também sair da floresta montado em um animal e simbolizando a resistência e mostrando que a comunidade ainda vive, trazendo a esperança.

Bosi (1996, p. 118) ressalta que "resistência é um conceito originariamente ético, e não estético. O seu sentido mais profundo apela para a força da vontade que resiste a outra força, exterior ao sujeito. Resistir é opor a força própria à força 
alheia". Nesse contexto, Cardoso (2004) se utiliza da sua escrita para representar o bem e o mal, utilizando um personagem como mensagem de esperança.

O narrador cria, segundo o seu desejo, representações do bem, representações do mal ou representações ambivalentes. Graças à exploração das técnicas do foco narrativo, o romancista poderá levar ao primeiro plano do texto ficcional toda uma fenomenologia de resistência do eu aos valores ou antivalores do seu meio. Dá-se assim uma subjetivação intensa do fenômeno ético da resistência, o que é a figura moderna do herói antigo. Esse tratamento livre e diferenciado permite que o leitor acompanhe os movimentos não raro contraditórios da consciência, quer das personagens, quer do narrador em primeira pessoa (BOSI, 1996, p. 121-122).

Uma das possibilidades de compreensão do conto $A$ morte do Velho Kipacaça está no fato de que durante séculos Angola sofreu com a colonização europeia, e o conto apresenta esse processo de libertação. Eis a resistência. Seguindo as fases de desenvolvimento da literatura angolana, que vão da alienação até a independência, quando os escritores passaram a se afirmar culturalmente, libertando-se da colonização, como sugere Laranjeira (2017, p. 28):

\footnotetext{
A Angola moderna, atual, é o resultado da atitude de revolta contra os estrangeiros - portugueses ou holandeses - levada a cabo por Nzinga Mbandi, que unificou a região de maioria quimbundo, onde o MPLA viria a surgir, também naturalmente, como a emanação dessa região e etnia, alargada ao resto do território atual, de que emergiu a elite sociológica mestiça, negra e branca que liderou o processo da independência.
}

A morte do velho Kipacaça apresenta a luta do povo angolano para manter suas tradições. Há uma tentativa de apagamento do homem forte, lutador, caçador, ao decretarem sua morte, enquanto o povo da aldeia parte em busca de um corpo desaparecido e que poderia acabar de vez com a falta de chuva e perecimento dos aldeões. Apagar o caçador seria fazer desaparecer o símbolo da resistência, enquanto o povo sofre as consequências de sua ausência, de quem poderia salvá-los da má sorte. No caso, a falta de chuva, que também pode representar a ausência de abundância, já que a chuva (água) sugere vida.

Seria Kipacaça a representação do povo angolano, o qual sofria um apagamento, ante a tentativa do colonizador europeu de transformá-lo também em europeu? Enquanto as pessoas buscavam a identidade de um povo guerreiro, lutador, iam revendo sua história e suas tradições para descobrir que ainda restava esperança. Resistir era o melhor a se fazer. Cardoso (2004) apresenta ambientes familiares para provocar no leitor o sentimento de pertencimento. Silva (2009, p. 54), ao falar das raízes arquetipais, diz que elas 
Constituem o lastro universal, espécie de magma interno, intenso e fervilhante, que, vindo à superfície, multiplica-se em histórias aparentemente tão diversas, em tantas línguas distintas, com tantos cenários diferentes, exóticos ou familiares. Familiares mesmo são os sentimentos que essas raízes despertam, as questões que suscitam, as comoções internas que provocam no leitor.

É, nesse caso, o sentimento de identidade, de pertencimento àquele lugar e àquela história que emerge. É quando, depois de muito andarem, de não saberem o que fazer para resolver o problema, surge Kipacaça, imponente, montado em um animal, com um fogo nas mãos, restaurando a força de cada um para dizer que é preciso lutar. $\mathrm{O}$ animal representa a força, a união do homem com a natureza e consigo. É a identificação com a possibilidade de superação dos desafios que está em evidência.

E o assassino do velho caçador acaba sufocado pelo brado do povo que reage e se conscientiza de sua herança cultural e social, mostrando uma Angola viva, onde a resistência faz parte desse povo. Dessa forma, através da união é possível enfrentar as dificuldades que surgem e manter suas tradições sem se render aos costumes estrangeiros.

\section{Considerações finais}

As tradições orais no conto se tornam cruciais para criar um clima de aproximação entre o leitor e a cultura angolana, visto que elas fazem parte da vivência de um povo. As histórias são repassadas de geração para geração pelos mais velhos, os guardiões da memória do povo. Assim, os recursos utilizados por Boaventura Cardoso (2004) contribuem para a identificação da resistência do povo na luta contra a modernização imposta pelo colonizador.

Em $A$ morte do velho Kipacaça, a simbologia está presente na oralidade, ao apresentar falas semelhantes ao que se vivencia no dia a dia; nas crendices, como no fato de descobrir através do sonho que algo ruim iria acontecer; na bebida como estratégia para descobrir quem matou Kipacaça; na roda dançante como preparação para a entrada do espírito do caçador montado em um animal, e no fogo, visto como purificador de ambiente.

O conto simboliza também a resistência do povo angolano frente ao colonizador, que tenta apagar tradições culturais como forma de demonstrar seu poder. Ao fazer isso, o povo resiste e consegue manter viva sua história e sua cultura. 


\section{Referências}

BAKHTIN, Mikhail; (VOLOCHÍNOV, V. N.). Marxismo e Filosofia da Linguagem: Problemas Fundamentais do Método Sociológico na Ciência da Linguagem. 6. ed. São Paulo: Hucitec, 1992.

BANDEIRA, Manoel. Estrela da vida inteira. 20. ed. Rio de Janeiro: Nova Fronteira, 1993.

BOSI, Alfredo. História concisa da literatura brasileira. 50. ed. São Paulo: Cultrix, 2015.

BOSI, Alfredo. Narrativa e resistência. Itinerários, nº 10, Araraquara, 1996.

CARDOSO, Boaventura da Silva. A morte do velho Kipacaça. Luanda: Edições Maianga, 2004.

CUNHA, Maria Zilda da. Na tessitura dos signos contemporâneos: novos olhares para a literatura infantil e juvenil. São Paulo: Editora Humanitas; Paulinas, 2009.

ESCOLA KIDS. Caipora. Disponível em: https://escolakids.uol.com.br/historias/caipora-1.htm. Acesso em: 28 nov. 2019.

FERREIRA, Guadalupe Estrelita dos Santos Menta. Literatura e história em Boaventura Cardoso. Cadernos Cespuc. Belo Horizonte, n. 19, 2010.

FONSECA, Maria Nazareth Soares; MOREIRA, Terezinha Taborda. Panorama das Literaturas Africanas de Língua Portuguesa. Cadernos Cespuc de Pesquisa: Série Ensaios, Belo Horizonte, v. 1, n. 16, p. 13-69, set. 2007.

GUIMARÃES ROSA, João. Grande Sertão: Veredas. 1. ed. Rio de Janeiro: Nova Fronteira, 2006.

LARANJEIRA, Pires. Pós-colonialismo e pós-modernismo em contexto pré-moderno e moderno - o local e o nacional nas literaturas dos cinco e as ilusões da literatura-mundo. Revista de Estudos Literários. Literaturas africanas de língua portuguesa. v. 5, 2017.

FONSECA, Maria Nazareth Soares; MOREIRA, Terezinha Taborda. Panorama das Literaturas Africanas de Língua Portuguesa. Cadernos Cespuc de Pesquisa: Série Ensaios, Belo Horizonte, v. 1, n. 16, p. 13-69, set. 2007.

PARREIRAS, Ninfas. Confusão de línguas na literatura: o que o adulto escreve, a criança lê. Belo Horizonte: RHJ, 2009.

PAGANINI, Nilze. Círculos concêntricos: a morte do velho Kiapaça. Caderno Cespuc de Pesquisa. Belo Horizonte, n. 16. p. 97-104, set. 2007.

PORTO, Ana Paula Teixeira. Cultura e literatura africana de Angola: diálogos ininterruptos. Revista Prâksis, Novo Hamburgo, v. 1, p. 9-16, nov. 2016.

SARAIVA, Sueli. Boaventura Cardoso e o romance angolano: revisto e atualizado. Revista de Letras, no 35, vol. 1. jan./jul. 2016. 
SILVA, Maurício. Angola, Moçambique e Cabo Verde: uma introdução à prosa de ficção da África lusófona. Nau Literária: crítica e teoria de literaturas. Porto Alegre. vol. 7. n. 1, jan./jun. 2011.

SILVA, Vera Maria Tietzmann. Literatura infantil brasileira: um guia para professores e promotores de leitura. 2. ed. rev. Goiânia: Cânone Editorial, 2009.

SOARES, Francisco. Notícia da literatura angolana. Escritores dos países de língua portuguesa. Imprensa Nacional - Casa da Moeda, 2001. 